Research Article

\title{
Intelligent Recognition of Safety Risk in Metro Engineering Construction Based on BP Neural Network
}

\author{
Mengchu Li iD and Jingchun Wang \\ School of Civil Engineering, Shijiazhuang Tiedao University, Shijiazhuang 050043, Hebei, China \\ Correspondence should be addressed to Jingchun Wang; wjc36295@163.com
}

Received 15 January 2021; Revised 6 April 2021; Accepted 13 April 2021; Published 3 May 2021

Academic Editor: Ming Bao Cheng

Copyright (c) 2021 Mengchu Li and Jingchun Wang. This is an open access article distributed under the Creative Commons Attribution License, which permits unrestricted use, distribution, and reproduction in any medium, provided the original work is properly cited.

\begin{abstract}
With the rapid development of urban economy, the development of urban rail transit is becoming more and more rapid. As an energy-saving, land-saving, and environment-friendly green travel mode, the subway provides realistic and feasible solutions to the increasingly prominent traffic environment and other urban diseases in our country and brings a booming development in the subway construction industry with efforts to promote and build in many large cities. For a large number of subway constructions, it is particularly important to judge the construction safety status in time during the entire safety management process. Regularly conducting safety risk assessments on subway construction status can accurately predict and judge the types of accidents that occur. In order to solve the current safety risk assessment problems in the process of subway construction in our country, this paper is based on the BP neural network to intelligently identify the safety risks of subway construction, choosing from three aspects: human factors, management factors, and risk factors. We evaluate the construction safety of subway projects under construction through the model, predict the types of accidents that may occur, so that the construction unit can take corresponding preventive and improvement measures, improve the relevant safety technology of subway construction in a targeted manner, and propose corresponding reductions. We provide suggestions and measures for risk probability, to ensure that the construction unit discovers the danger in time and takes safety measures. The rectification measures provided theoretical basis and guidance.
\end{abstract}

\section{Introduction}

1.1. Background and Significance. With the rapid economic growth and rapid population growth, the scale of transportation and the density of people's travel have increased, and urban transportation has brought new huge overload pressure [1]. With the subway as the main mode of operation, it not only relieves the traffic and traffic congestion in the city but also changes the role of people's lifestyle and travel mode [2]. The construction of the subway has the characteristics of concealment, complexity, and uncertainty. Due to the rapid development of subway projects, the large scale of construction, and the lack of sufficient technology and management capabilities, the safe construction of subway projects has potential high safety hazards [3]. It has devastating effects on victims, property damage, and social environment. Therefore, it is very urgent to determine the dangerous factors in subway construction and formulate appropriate countermeasures to reduce or even eliminate possible safety accidents. The purpose of this article is to establish a safety assessment prediction model, through which the safety of underground projects under construction can be evaluated and the types of possible accidents can be predicted, so that the construction unit can take appropriate preventive and remedial measures [4].

1.2. Related Work and Research. McCulloch and Pitts introduced the M.P. model in their published article. Since the birth of this model, it has pioneered the theoretical research of neural network models [5]. Yang et al. discussed methods and strategies for solving uncertainty problems and discussed appropriate assumptions for comprehensive uncertainty analysis [6]. Based on multiple examples of 
engineering projects, Yang et al. started with system development, controllability, and independence and created a relatively conceptual framework based on project strategy [7]. By comparing different types of commonly used projects, the ability to predict risk and governance is improved $[8,9]$.

Ma of the United States applied risk analysis to tunnels and underground projects in 1970 [9]. Since then, foreign research on risk assessment methods and risk management theories has increased, and remarkable results have been achieved and widely used. He not only put forward the ideas to follow but also created a tunnel cost model based on computer simulation, the scope of which is limited to hard rock tunnels. The biggest innovation of this model is the increase of uncertainty in the project budget, so it is very suitable for actual engineering [10]. Tsai et al. have proposed an engineering risk management model for the Amsterdam North-South subway project, which is used to control the risks of technically complex underground projects [11]. It has gone through various stages of project design and construction, including project quality, duration, and cost [12].

Our country has held many informal seminars on neural networks [13]. The "First Academic Conference on Neural Networks in China" jointly organized by eight companies including our country's computer companies and artificial intelligence companies was held in Beijing. Yiming et al. introduced the process and method of risk management combined with subway construction and explained the practicality and convenience of applying risk management methods in subway construction [14]. Han et al. analyzed the causes of domestic subway construction accidents in recent years, emphasized the importance of risk management in subway construction, summarized the characteristics of subway project risk management, and put forward suggestions on the content of subway risk management [15]. Longkang et al. introduced the risk index method in the risk assessment of mechanical tunnels, and it has been widely used in mechanical tunnels in our country [16]. Based on the system theory, Zeng et al. used dynamic control principles to study the theoretical framework of the subway project risk assessment system from the perspective of dynamic system risk assessment [17-19]. There are some shortcomings in the experimental research of the abovementioned scholars, so this paper studies the intelligent identification of safety risks in subway construction based on the BP neural network.

1.3. Innovation. This article introduces the $\mathrm{BP}$ neural network algorithm in the field of underground construction project risk analysis. It not only expands the scope of the BP neural network algorithm but also enriches the traditional management method system of the project management profession, which is practical. The theoretical significance and practical value of the application are studied.

This paper uses the advantages of the BP neural network in self-learning, nonlinear self-adaptation, approximation ability, etc. and, according to the subway engineering data sample, realizes the prediction of subway target risk to quickly and effectively assess the risks of subway construction and provide solutions to the risks of subway construction.

In order to reduce the dependence on personnel in the risk identification process and realize the intelligent automatic identification of construction safety risks, this paper, based on the cloud storage and cloud sharing functions of the building information model, deeply studies the preconstruction safety risk identification, proposes a subway station construction safety risk intelligent identification model, establishes a set the safety risk identification during the construction preparation period to the safety control technology system for prevention and control, and provides reference and support for realizing the safe construction of subway stations.

This article introduces the BP neural network algorithm to use the powerful nonlinear problem processing capabilities to provide better solutions for subway project risk analysis and to obtain analysis results faster, especially when there are many indicators, evaluation, and improvement The advantages of the BP neural network algorithm are more obvious.

This article introduces the importance of subway construction safety and current problems in the abstract section. In the second part of this article, the function of the BP neural network algorithm and its application in subway construction safety are introduced. In the third part of this article, we simulate the BP neural network algorithm in the subway construction. In the fourth part, the data are analyzed. Verification: the function of the BP neural network algorithm is verified.

\section{Method of Safety Risk Identification in Metro Engineering Construction}

2.1. BP Neural Network. The BP neural network structure is composed of an input layer, a hidden layer, and an output layer. The process of its learning algorithm is the forward propagation of information and the back propagation of errors [20]. Error back propagation refers to the difference between the expected value and the output value. Error: the output layer transfers it to the hidden layer according to the error gradient descent method and then passes it from the hidden layer to the input layer. The error signal is transmitted back along the original line through the network to correct the connection weight of each layer of neurons, thereby gradually approaching the goal [21]. The global minimum error is calculated, and it is determined whether the error meets the requirements. If the error is lower than the set accuracy, or if the number of training times is greater than the set maximum number of training times, the training ends; otherwise, the next learning sample is selected, and the next round is returned. Calculation: the forward propagation of information and the back propagation of errors make the weights of each layer to continuously selfadjust, and the entire network self-adaptively learns until the output error is less than the error target value or the set number of training times [22]. 
The working state of the BP neural network is mainly divided into two kinds of learning state and working state. The learning state is to continuously adjust the connection weights between neurons in each layer to make the network output more in line with the real situation; its working state means that the connection weights between the neurons in each layer no longer changes, and the built BP used the neural network model, input new data, and get prediction data. The BP neural network model establishes a nonlinear high-latitude functional relationship between the input factor and the output factor. This functional relationship is the result of the model training sample learning. Using this training result, new data are input outside the training sample, and we can get the correct output, that is, the prediction result, which is also the main idea of using the BP neural network to solve the problem in this article [23].

In a simple BP neural network structure, each neuron takes the output of the previous layer of neurons as input, outputs its own calculation results, and transmits it to the next layer as its input $[24,25]$. The BP neural network can be single layered or multilayered [13]. The neural network has an input layer, an output layer, and a hidden layer, as shown in Figure 1.

The neuron model in the BP neural network is similar to other neurons, so the general model structure diagram can refer to the form in the figure mentioned above. The difference lies in the transmission mode. BP neurons usually use nonlinear transfer functions, such as logsig and tansig functions, both of which are sigmoid functions, and their output values will be limited to $(0,1)[26]$. The standard BP network structure includes four parts: input and output, activation function, error calculation, and self-learning. The formula description is as follows:

(1) Input output: hidden layer node and output node output model.

$$
\begin{aligned}
N_{i} & =f\left(\sum A_{i j} \times B_{i}-z_{i}\right), \\
E_{k} & =f\left(\sum M_{j k} \times N_{j}-z_{k}\right),
\end{aligned}
$$

where $f$ is the nonlinear activation function; $z$ is the threshold of the neuron.

(2) Activation function: it mainly refers to the sigmoid function.

$$
f(x)=\frac{1}{(1+e)} .
$$

(3) Error calculation: in order to make the difference between the expected output of the network and the actual output meet the external expectations, the following function model can be used:

$$
E_{z}=\frac{1}{2} \times \sum\left(r_{s i}-n_{s i}\right)^{2}
$$

where $r_{s i}$ is the nonlinear activation function; $n_{s i}$ is the threshold of the neuron.

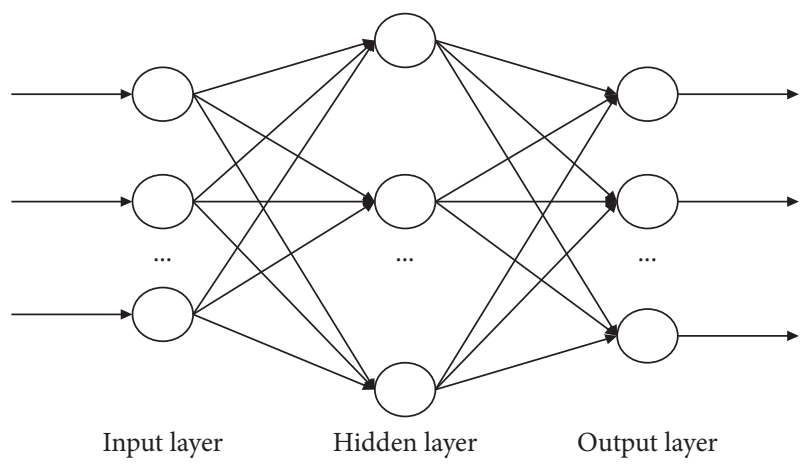

FIgURE 1: BP network model structure diagram.

The network learning process of the BP neural network can be described by Figure 2 .

In the process of system risk assessment, the BP neural network has the following advantages:

(1) The BP neural network adopts a parallel structure based on the human brain and has the characteristics of parallel processing, which can effectively overcome the influence of subjective factors and comprehensively evaluate the security status and interaction of the system. The safety in this case is multifunctional.

(2) Using the complementarity of the BP network knowledge storage function and appropriate learning samples, we can realize the complete combination of historical experience and new knowledge and dynamically evaluate the security status of the system development process.

(3) Using the sheep tolerance characteristics of the BP network method, it is possible to process various nondigital indicators while selecting appropriate functions and data structures to perform a fuzzy assessment of the security status of the system $[27,28]$.

2.2. Safety Risk and Identification of Subway Construction. Risk is usually an abstract and relatively vague concept [29]. It includes two main factors: risk sources and risk issues. It refers to the uncertainty of hazardous events that lead to potential risk losses. This uncertainty includes objective uncertainty and subjective uncertainty $[30,31]$. For objective uncertainty, one can use mathematical statistics to calculate. Subjective uncertainty is closely related to people's understanding of the risk event itself, the environment, and psychological state at the time, so the subjective risk perception of different individuals is still uncertain. The safety risk of subway construction refers to the threats that may occur during the entire process from the preparation stage of the subway project to its completion and acceptance stage [32].

From the perspective of risk uncertainty, the risk of a project can be defined as "The impact of project objectives (quality, cost, and duration) that may occur during the entire life cycle of the project and the possible interventions that 


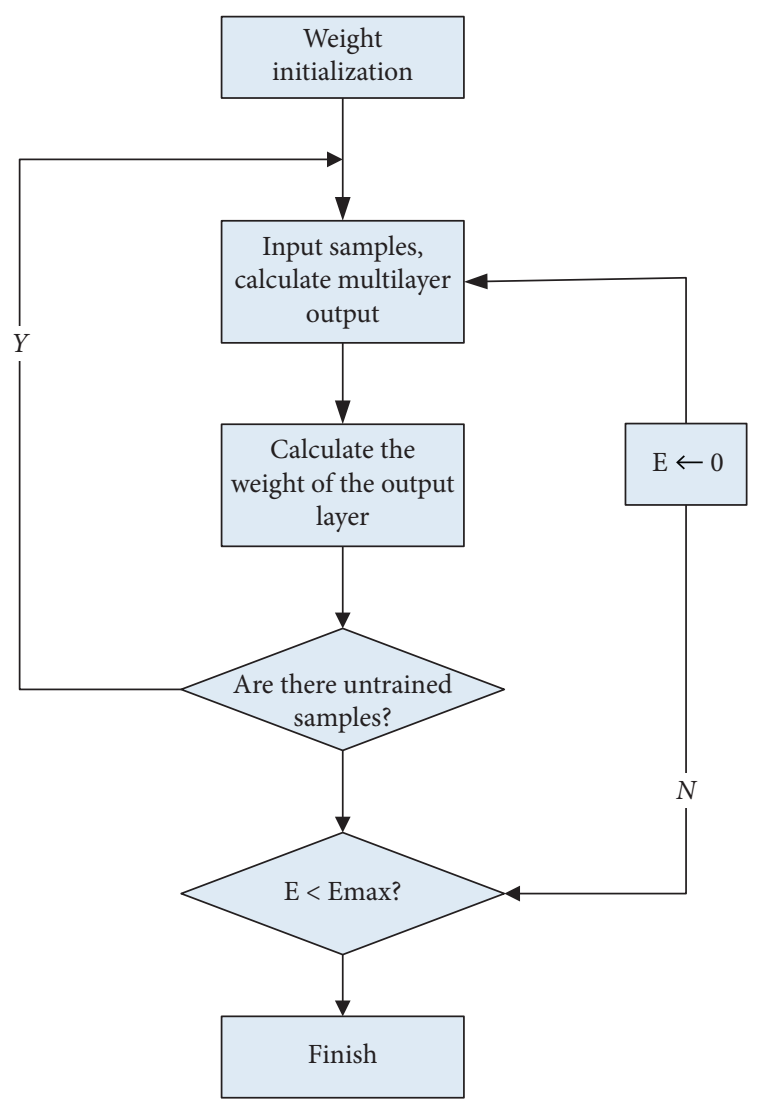

FIGURE 2: BP neural network flow chart.

may occur" in production and operations. In the process, uncertainty or the impact of events may cause damage or loss of mechanical operations [33]. The risk analysis and assessment process is shown in Figure 3.

The construction risk management of subway engineering refers to that in order to achieve the expected goals of quality, time, cost, and safety, the manager of the organization appropriately uses the basic risk management theory, including organization, design, coordination, and management. For control during the establishment of a deep foundation, the risks must be fully identified, analyzed, and evaluated, and preventive measures must be taken to reduce the possibility of risk events or reduce the adverse effects of the results [34]. Due to the objective existence of managerial subjective differences, the evaluation of objective risks and their potential impacts is unilateral. After completing the abovementioned risk identification, the risks must be analyzed and evaluated in detail. This is the whole process of risk management. An important link is also the link and bridge between risk identification and risk decision making, which is the key to risk management $[35,36]$.

The environment of the subway project and the construction site is complex and closely connected, interacting with and restricting each other. As an important part of the urban rescue project, it has high requirements for construction safety and construction quality. Due to the particularity of the subway construction site and the complexity of construction, the interface will contain many different

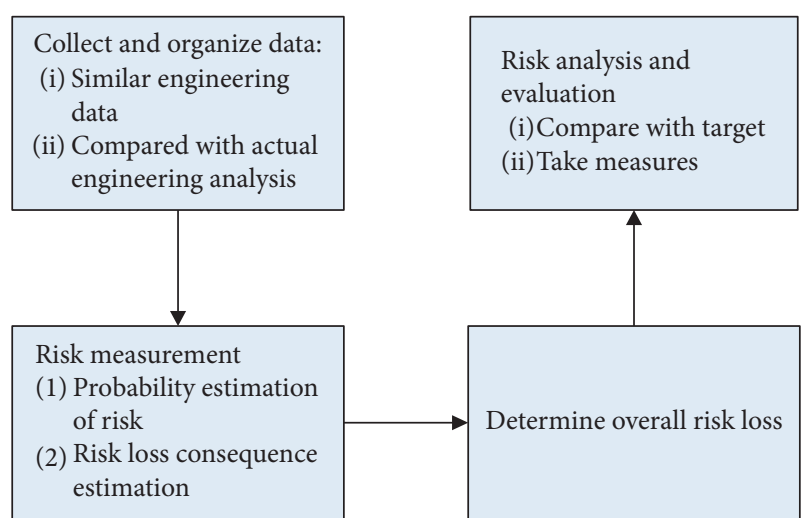

FIGURE 3: Risk analysis and estimation process.

aspects of the industry. The working area of a subway tunnel is completely different from that of buildings on the ground. The working space of the ground building is relatively wide, and the vertical and horizontal directions are combined, while the working space of the subway mechanical tunnel is mainly horizontal, and the working space is very narrow. These factors determine the longest construction period of the subway project. Urban subway is a kind of high-cost and high-cost underground transportation. There are mainly two types of overhead and underground space. The underground cost is mainly of high cost.

2.3. The Construction Safety Risk Assessment Index of Subway Engineering. Establishing a reasonable and effective risk assessment system can improve the accuracy of risk assessment and lay a good foundation for risk assessment and control.

On the basis of the existing subway project safety evaluation system, the risk factors that may affect the construction progress of the subway project are comprehensively analyzed, and the subway project construction evaluation system is established. In addition, considering the current risk factors caused by the ideas and technological innovation of each component, the innovative ideas and technological risks are taken as independent evaluation indicators to establish a risk evaluation system that best meets the requirements. In the construction of the subway, the basic principle of the index system proposed in this paper is verified through the analytic hierarchy process, which provides a theoretical basis for the next development and is more in line with the actual implementation requirements of the project [37].

In the process of risk assessment of subway project construction, not only should the identification and control of risk indicators be strengthened but also reasonable risk assessment standards should be formulated. Determining the risk level of subway construction can help decision makers familiarize themselves with the adverse effects of subway incidents and promote risk prevention. According to the literature review, this article also determines the following five risk levels in conjunction with the actual construction of the subway project, as shown in Table 1 . 
TABLE 1: Risk levels of subway construction.

\begin{tabular}{lcc}
\hline Risk level & Interval range & Meaning \\
\hline Level 1 & $(0,0.2]$ & Acceptable and strive to control the risk within this level \\
Level 2 & $(0.2,0.4]$ & Acceptable, it is allowed to occur within certain conditions without escalating the risk level \\
Level 1 & $(0.4,0.6]$ & Do not want to happen; compare the adverse effects of risks and the cost of measures taken \\
Level 4 & $(0.6,0.8]$ & Unacceptable; immediately formulate risk response measures \\
Level 5 & $(0.8,1]$ & Completely unacceptable; eliminate or avoid risks \\
\hline
\end{tabular}

Establishing a project risk assessment system is an important task. The quality, rationality, and completeness of the company directly affect the results of the risk assessment. Therefore, it is very important to establish a logical, scientific, practical, and objective engineering risk assessment system. The special complexity of the subway itself, coupled with the various natural and man-made environments in which it is located, makes it even more complicated. It can be said that the risk of a subway project is a complete system, so the establishment of a risk assessment index system must also comply with this systematic principle. When selecting indicators, the factors affecting mechanical hazards should be considered as comprehensively as possible, and evaluation indicators should be considered in a stable process. Evaluation indicators must be considered systematically. In order to build an organic whole, various dynamic and static indicators should be combined for qualitative and quantitative analysis. Only in this way can the final assessment result more fully reflect the risks of the subway project [38].

\section{Safety Risk Identification Experiment of Subway Construction}

This article discusses the issue of subway construction safety assessment. It is easy to know that each influencing factor, namely, the safety factor index, has a different degree of influence on the safety level of the assessed item. At the same time, the construction of groundwater works in each region follows the surrounding rocks, hydrogeological sites, monasteries, political zones, and much more. In addition, expectations for the safety of an underground project should also be different.

3.1. Test Subject. This paper selects 15 existing subway projects as samples for research and determines the selection of subway projects based on the BP neural network construction method. Therefore, this paper selects 15 groups of cities under construction in A, B, C, D, and E cities. For the subway project, the study continued to invite 8 professionals in the industry who participated in the risk factor identification questionnaire to analyze and identify 12 risk evaluation index systems established for 10 projects.

3.2. Test Design. Safety management of the subway construction organization: the construction party involved in this article is the construction unit. The safety management of the subway construction organization refers to the organization safety management of the construction unit. Organizational safety management is mainly realized through the construction unit's institutional functions, guarantee measures, and system constraints [39]. Organizational safety management restricts and guides human behavior from the management level, reduces the probability of unsafe behaviors, and standardizes construction behavior. Therefore, when evaluating indicators, the safety management indicators of subway construction organization are divided into construction site safety management, three evaluation items of safety production system, and safety management organization.

The idea of calculating the weight in this section is the number of evaluation index levels is 3 levels, first calculating the weight value of the standard level at the target level, then calculating the weight value of the index level in the corresponding standard, and finally, calculating the value of the single-layer weight combination. To obtain the total weight, we take the total weight of the index level index as the target level.

(1) We inquire and collect knowledge about safety risks in the construction specifications of subway projects published in our country and scientific papers and documents at home and abroad

(2) We transform risk knowledge into computer expressions

(3) Based on cloud information technology of building information technology, we complete the construction of a knowledge base of hidden dangers in subway construction and accumulate and share the knowledge base

(4) Based on the established knowledge base on the safety of subway structure, we intelligently extract the technical data of the BIM subway model and read the technical parameters of the various rules related to the various dangers of the subway station

(5) use the credibility combination analysis method to formulate intelligent identification rules

The criterion layer calculates the weight of the target layer. The criterion layer is four indicators of organizational safety management, technical safety management, environmental safety management, and personnel safety management, which are represented by $T_{1} T_{2} T_{3} T_{4}$ in turn and assigned values according to the importance of the target layer. Through pairwise comparison, the judgment 
matrix $Z$ of the target layer and the criterion layer is established:

$$
Z=\left[\begin{array}{llll}
1 & \frac{1}{3} & 3 & 2 \\
3 & 1 & 4 & 2 \\
\frac{1}{3} & \frac{1}{4} & 1 & \frac{1}{3} \\
\frac{1}{2} & \frac{1}{2} & 3 & 1
\end{array}\right] .
$$

The consistency test is performed through the relevant formula. If the consistency ratio is less than the specified 0.10 , it indicates that the consistency of the crisis matrix is good and the weight distribution of each indicator meets the requirements. Otherwise, it indicates that the distribution of the matrix is unreasonable, the degree of dispersion is large, and the crisis is not accurate. At this time, the weight of the rating index should be modified and then recalculated:

$$
\begin{aligned}
& A M=\frac{\left(\alpha_{\max }-q\right)}{(q-1)}=\frac{(3.112-3)}{(3-1)}=0.056, \\
& A N=\frac{(A \times M)}{(N \times M)}=\frac{0.056}{0.9}=0.059<0.1 .
\end{aligned}
$$

3.3. Experimental Results. According to the identification results of safety hazards, potential hazards include instability of the foundation pit steel structure, instability of the foundation pit supporting structure, flowing soil and punches under the foundation pit, harmful geological conditions, and leakage and cracks. The construction team took many effective measures. Obviously, the construction of subway projects in each region depends on the surrounding rock structure soil, geological and hydrogeological conditions, management agencies, and local policy environment in different regions. The site was arranged in advance, and the entire construction work of the subway with emergency teams and various emergency equipment was safe and smooth, and good implementation results were achieved. Based on this BIM model of subway construction, the results of intelligent hazard identification using the reliability combination analysis method are given as shown in Table 2.

\section{Related Analysis of Safety Risks in Subway Construction}

4.1. Questionnaire for Risk Assessment of Metro Engineering Construction. We pay attention to the intersection of the two types of samples during network training because the central input of the same type of samples will cause the network to only determine the mapping relationship suitable for this type of sample during the training and determination process. When other types of samples are concentrated, the network weight value adjustment will move to the new mapping relationship, and the previous training results will be cancelled. In this article, according to the
Matlab2012a Neural Network Toolkit, it is called the BP Neural Network. Through the construction sample data of 15 subway projects in specific locations, including construction cost, pile quality, slope instability, long inspection cycle, house deformation, pipeline, and fast sand, all aspects of the data have been integrated and organized, and finally, the sample training data that have been researched and analyzed are introduced into the BP training program. The value-added evaluation and change risk curve of the mechanical deep base mirror are shown in Figure 4.

4.2. Types of Accidents in Subway Construction. Most construction accidents are not isolated, but a variety of accidents occur together, or the occurrence of other accidents due to one type of accident will eventually cause casualties to the masses and adversely affect social life. Due to limited data collection, reliable information is mainly obtained through media reports and related materials. For accidents that have no social impact but frequently occur (such as falling from a height), the device will have a certain degree of concealment, and the outside world will not be able to obtain related types of accidents. In terms of accident statistics, there were 12 collapse accidents, with the largest number of accidents, followed by collapses, pipeline damage, and mechanical accidents. These three accidents are also more common, with 6 cases, 6 cases, and 5 cases respectively. In the past four years, there have been frequent shootings and fires. The most common subway construction accidents are collapses, pipeline damage, and mechanical accidents. It seems that we should not only focus on the types of accidents that cause deaths and injuries but also ignore the types of accidents without casualties. This is incorrect because the mechanism of construction accidents is the same, but the consequences are different. Through incomplete statistics of China's subway construction accidents in the past five years, the results are shown in Figure 5.

4.3. Characteristics of Environmental Risk Factors. Due to the uncertainty of system behavior during normal subway construction, mechanical accidents may be caused, which is not conducive to subway construction. Underground engineering is a large-scale urban construction project. The construction process is very complicated and involves many risk factors. Geological hazards, environmental hazards, construction hazards, etc. are caused by the upcoming subway construction. Most subway lines pass through complex areas, such as the old city and shopping areas. There are many types of buildings along the line, such as houses, viaduct foundations, underground passages, and underground passages. The surrounding environment along the line is more complicated. According to the evaluation model and risk level standards, and when determining the weights, relevant experts and experienced technicians are first required to evaluate to determine the probability of occurrence of all risk factors and the extent of potential risks at the factor level. The estimated values are shown in Table 3.

As shown in Table 3, the risk assessment of subway construction projects can be divided into 5 levels. When the 
TABLE 2: Risk intelligent identification results.

\begin{tabular}{lccc}
\hline Security risk classification & Rule coding & Risk description & Credibility \\
\hline & R1-2 & Quicksand & 0.7 \\
Construction technology risk factors & R1-27 & Unstable steel structure of foundation pit & 0.49 \\
& R1-16 & Unstable foundation pit retaining structure & - \\
Project characteristics risk factors & - & Harmful geological conditions & - \\
Geological and hydrological risk factors & R3-02 & Leaks and cracks in underground pipelines & 0.33 \\
Risk factors of construction environment & R4-14 & 0.28 \\
\hline
\end{tabular}

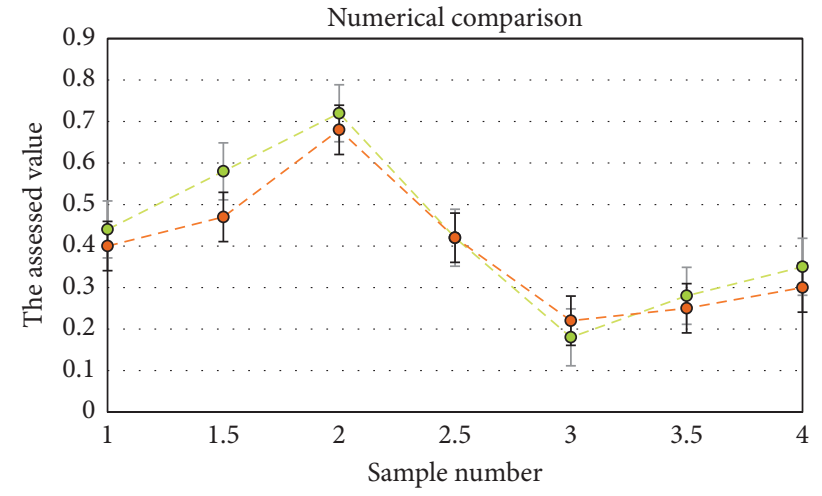

- - Actual output value

- o- Expected output value

FIGURE 4: Risk assessment value of subway construction.

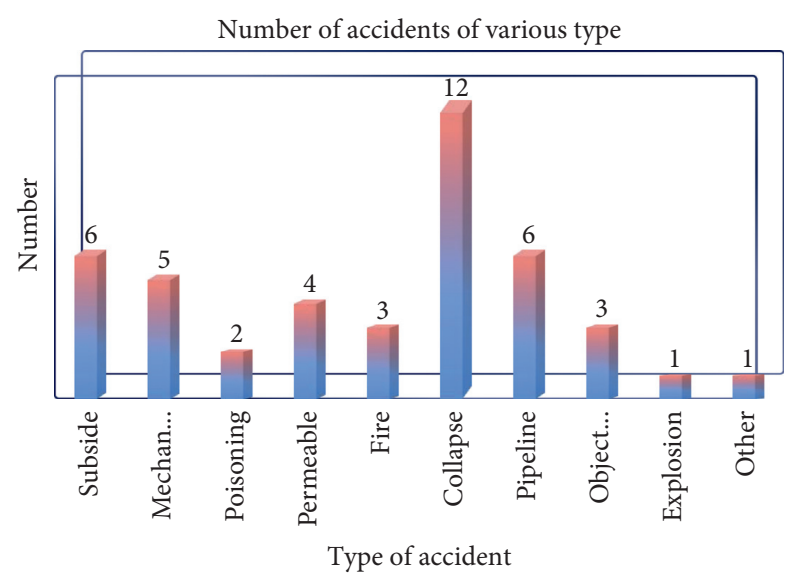

- Number of accidents

FIgURE 5: Statistics of accident types in subway construction.

TABLE 3: Classification criteria for risk level S.

\begin{tabular}{lcc}
\hline Grade & Valuation S & Meaning description \\
\hline Level 1 & $0.8-1.0$ & The highest level of risk, which may cause devastating disasters and heavy casualties \\
Level 2 & $0.6-0.8$ & The level of risk is very high, causing widespread damage or casualties \\
Level 3 & $0.4-0.6$ & The risk level is relatively high, which may cause damage within a certain range \\
Level 4 & $0.2-0.4$ & The risk level is low, and appropriate preventive measures can be taken \\
Level 5 & $0-0.2$ & The lowest level of risk, almost no risk \\
\hline
\end{tabular}




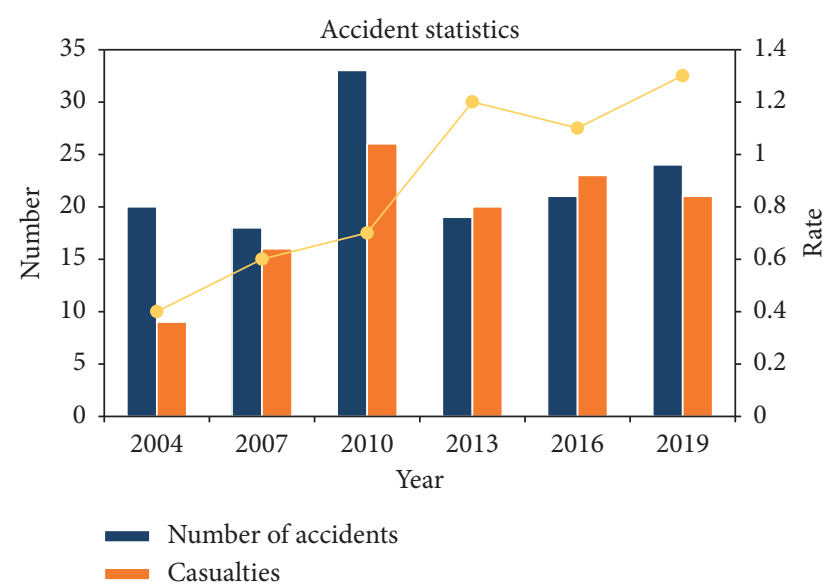

FIGURE 6: Statistics of our country's subway construction accidents from 2014 to 2019.

valuation is $0.8-1.0$, the subway construction risk is the highest, and when the valuation is $0-0.2$, the subway construction risk is the lowest.

\subsection{Statistics of Our Country's Subway Construction Acci-} dents in Recent Years. At present, the conduct of our country's subway is at its peak. Since the design of the subway, there have always been multiple risk factors. The construction of the subway is scattered and involves many builders. If an accident occurs, it may cause serious personal and property damage. During the subway construction process, the complexity of rocks and ground and the unpredictable state of unknown objects, the complexity of the construction process and construction equipment, the concealment of the project, the length of the construction period, and the uncertainty of the construction process risk have all increased. The total number of subway construction accidents is also increasing year by year. Therefore, the establishment of a subway construction risk assessment system can clarify the sources of danger in the subway construction process and reduce the occurrence of subway accidents. Figure 6 shows the statistical results of China's subway construction accidents from 2004 to 2019.

According to the data in Figure 6, it can be seen that, in 2004 , the number of accidents was 20, with the lowest mortality rate. In 2010, the number of accidents was 33 with the highest mortality rate. In 2007, the number of accidents was the lowest with 18 .

4.5. Percentage of Accidents in Each Month. According to the statistical results of domestic and foreign subway construction accidents and related research results, the subway construction process mainly includes safety accidents such as collapse, object hit, fall from height, lifting injury, and mechanical accident. In these 16 years, we can see the highest number of subway construction accidents occurred in March and May, July-August, and November; February was the lowest, and the number of adjacent months has changed greatly. From July to August, the

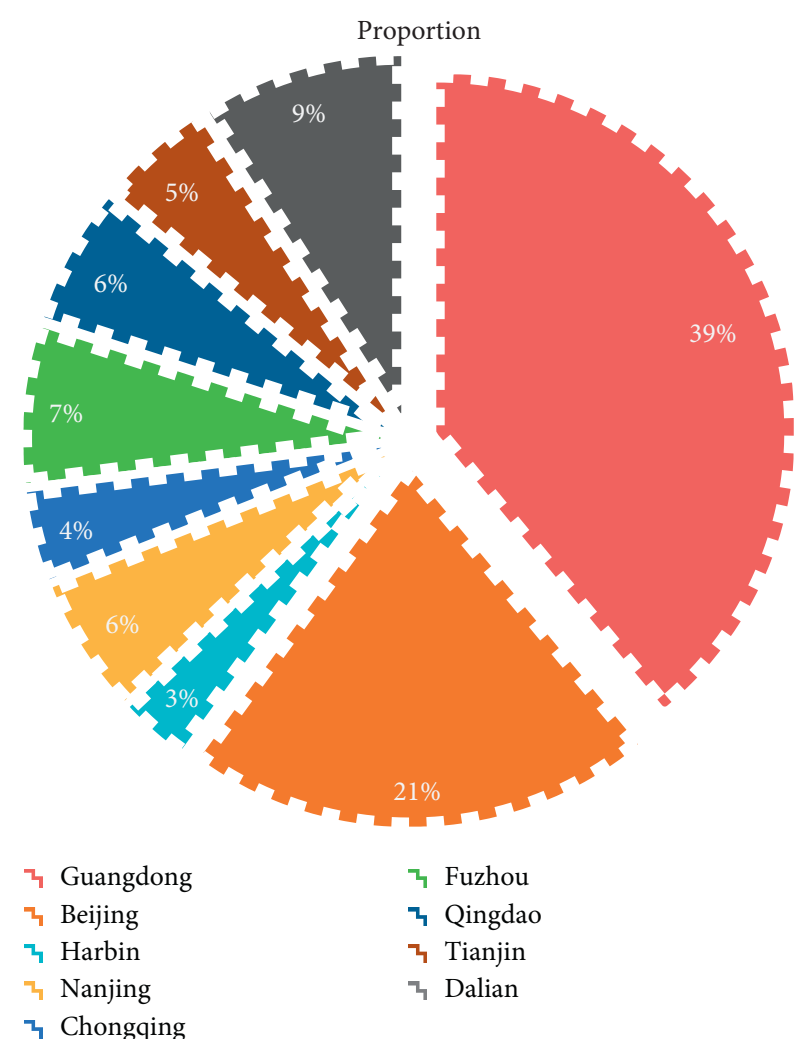

Figure 7: Proportion of locations where accidents occurred in March.

weather in our country is the hottest, the daytime is long, and the outdoor working environment is bad, which has become the peak of accidents. The accidents in November were mainly concentrated in cities in the middle and lower reaches of the Yangtze River. Due to weather changes, the number of rainy days exceeds 20 days, and the total number of accidents and casualties is also the highest. The Guangdong subway accidents in March mainly occurred in Guangzhou and Shenzhen, accounting for $40 \%$ of the country. The weather in Guangdong gradually warmed up in March, and the rain began to increase. There were many rivers in Guangzhou and Shenzhen, and the ground was loose, which also increased the safety risks of subway construction, as shown in Figure 7.

\section{Conclusions}

Safety assessment and prediction research during the subway construction stage can identify major risks in advance based on the analysis results, improve the management, and control capabilities and early warning capabilities of subway construction, thereby improving the safety level of the construction site and reducing accidents during the construction of the subway in our country. Avoiding or reducing losses and financial losses as much as possible to provide safety guarantees for the promotion of China's urban rail transit construction is of great theoretical significance for the comprehensive subway safety assessment in the future. 
On the basis of summarizing the existing research results and combining the construction characteristics of subway projects, this study constructed a set of index systems consistent with the risk analysis of subway construction progress and introduced the improved BP neural network algorithm into the risk preassessment. It has theoretical research significance and practical application value, takes the risk of conceptual technological innovation as an independent evaluation index, and has established a set of progress evaluation index systems that is more in line with the characteristics of current construction projects. This will help subway construction projects to more completely and accurately identify the risk factors that may occur during the construction process and to preconfigure countermeasures to reduce the possibility of efficiency hazards and their impact.

The improved BP neural network algorithm analyzes the risks in the construction of subway projects, and the feasibility of the intelligent risk identification model is analyzed and demonstrated. This model is actually applied to subway stations, and appropriate risk prevention and control measures are taken according to the identification results, which effectively reduces the occurrence of construction safety risk accidents and safely realizes the goal of safe construction of subway stations.

\section{Data Availability}

The data that support the findings of this study are available from the corresponding author upon reasonable request.

\section{Conflicts of Interest}

The authors declare that they have no conflicts of interest.

\section{References}

[1] J. Yang, J. Zhang, and H. Wang, "Urban traffic control in software defined internet of things via a multi-agent deep reinforcement learning approach," IEEE Transactions on Intelligent Transportation Systems, vol. 4, no. 3, pp. 177-188, 2010.

[2] H. Liu, B. Liu, H. Zhang, L. Li, X. Qin, and G. Zhang, "Crowd evacuation simulation approach based on navigation knowledge and two-layer control mechanism," Information Sciences, vol. 436-437, pp. 247-267, 2018.

[3] Y. Zou, B. Lin, X. Yang, L. Wu, M. Muneeb Abid, and J. Tang, "Application of the bayesian model averaging in analyzing freeway traffic incident clearance time for emergency management," Journal of Advanced Transportation, vol. 2021, no. 4, Article ID 6671983, 9 pages, 2021.

[4] Y. Sun, "Green and reliable freight routing problem in the road-rail intermodal transportation network with uncertain parameters: a fuzzy goal programming approach," Journal of Advanced Transportation, vol. 2020, no. 3, Article ID 7570686, 21 pages, 2020.

[5] M. Li, H. Yu, and P. Liu, "An automated safety risk recognition mechanism for underground construction at the preconstruction stage based on BIM," Automation in Construction, vol. 91, pp. 284-292, 2018.
[6] L. Yang, X.-R. Wen, X.-L. Wu et al., "Height prediction of water flowing fractured zones based on BP artificial neural network," Journal of Groundwater Ence and Engineering, vol. 7, no. 4, pp. 354-359, 2019.

[7] J. Yang, J. Wen, and B. Jiang, "Blockchain-based sharing and tamper-proof framework of big data networking," IEEE Network, vol. 34, no. 4, pp. 62-67, 2020.

[8] B. Wu, S. Han, J. Xiao, X. Hu, and J. Fan, "Error compensation based on BP neural network for airborne laser ranging," Optik, vol. 127, no. 8, pp. 4083-4088, 2016.

[9] Y.-H. Yuan, S.-H. Tsao, J.-T. Chyou, and S.-B. Tsai, “An empirical study on effects of electronic word-of-mouth and Internet risk avoidance on purchase intention: from the perspective of big data," Soft Computing, vol. 24, no. 8, pp. 5713-5728, 2020.

[10] D. Ma, T. Zhou, J. Chen, S. Qi, M. Ali Shahzad, and Z. Xiao, "Supercritical water heat transfer coefficient prediction analysis based on BP neural network," Nuclear Engineering and Design, vol. 320, pp. 400-408, 2017.

[11] S.-B. Tsai, Y.-Z. Xue, P.-Y. Huang et al., "Establishing a criteria system for green production," Proceedings of the Institution of Mechanical Engineers, Part B: Journal of Engineering Manufacture, vol. 229, no. 8, pp. 1395-1406, 2014.

[12] Z. Cheng and T. Juncheng, "Adaptive combination forecasting model for China's logistics freight volume based on an improved PSO-BP neural network," Kybernetes, vol. 44, no. 4, pp. 707-710, 2015.

[13] C.-H. Chen, F. Song, F.-J. Hwang, and L. Wu, "A probability density function generator based on neural networks," Physica A: Statistical Mechanics and its Applications, vol. 541, Article ID 123344, 2020.

[14] L. Yiming, H. U. Zhuowei, Z. Wenji et al., "Research on spatial characteristics of regional poverty based on BP neural network: a case study of wuling mountain area," Journal of GeoInformation Science, vol. 17, no. 1, pp. 69-77, 2015.

[15] X. Han, X. Xiong, and F. Duan, "A new method for image segmentation based on BP neural network and gravitational search algorithm enhanced by cat chaotic mapping," Applied Intelligence, vol. 43, no. 4, pp. 855-873, 2015.

[16] W. Longkang, R. Tingxiang, N. Baisheng et al., "Development of a spontaneous combustion TARPs system based on BP neural network," International Journal of Mining Ence \& Technology, vol. 25, no. 5, pp. 803-810, 2015.

[17] X. H. Zeng, G. H. Li, D. F. Song et al., "Rollover warning algorithm based on genetic algorithm-optimized BP neural network," Huanan Ligong Daxue Xuebao/Journal of South China University of Technology (Natural Science), vol. 45, no. 2, pp. 30-38, 2017.

[18] L. M. T. Pham, L. T. T. Tran, P. Thipwong, and W. T. Huang, "Dynamic capability and organizational performance," Journal of Organizational and End User Computing, vol. 31, no. 2, pp. 1-21, 2019.

[19] M. Abdel-Basset, R. Mohamed, M. Elhoseny, and V. Chang, "Evaluation framework for smart disaster response systems in uncertainty environment," Mechanical Systems and Signal Processing, vol. 145, Article ID 106941, 2020.

[20] Y. Chen, W. Zheng, W. Li, and Y. Huang, "The robustness and sustainability of port logistics systems for emergency supplies from overseas," Journal of Advanced Transportation, vol. 2020, Article ID 8868533, 10 pages, 2020.

[21] X. Chen, T. Wang, and W. Liang, "General aircraft material demand forecast based on PSO-BP neural network," International Journal of Control and Automation, vol. 9, no. 5, pp. 407-418, 2016. 
[22] H. Song and M. Brandt-Pearce, "A 2-D discrete-time model of physical impairments in wavelength-division multiplexing systems," Journal of Lightwave Technology, vol. 30, no. 5, pp. 713-726, 2012.

[23] Y. Cui, X. L. Ma, and Z. Liu, "Application of improved BP neural network with correlation rules in network intrusion detection," International Journal of Security and Its Applications, vol. 10, no. 4, pp. 423-430, 2016.

[24] S. Zhang, J. Lv, X. Yuan et al., "BP neural network with genetic algorithm optimization for prediction of geo-stress state from wellbore pressures," International Journal of Computational Intelligence \& Applications, vol. 15, no. 3, pp. 80-85, 2016.

[25] X. Li, Y. Wang, and G. Liu, "Structured medical pathology data hiding information association mining algorithm based on optimized convolutional neural network," IEEE Access, vol. 8, no. 1, pp. 1443-1452, 2020.

[26] Y. Q. Liu, Q. Xu, D. Infield et al., "Fault identification of wind turbine drivetrain using BP neural network based on gravitational search algorithm," Zhendong Yu Chongji/Journal of Vibration and Shock, vol. 34, no. 2, pp. 134-137, 2015.

[27] L. Yongkui, H. Yi, X. Bo et al., "Proactive behavior-based system for controlling safety risks in urban highway construction megaprojects," Automation in Construction, vol. 95, pp. 118-128, 2018.

[28] Y. Tang and M. Elhoseny, "Computer network security evaluation simulation model based on neural network," Journal of Intelligent and Fuzzy Systems, vol. 37, no. 3, pp. 3197-3204, 2019.

[29] C. Caldas, G. Gibson, A. M. Yohe, R. Weerasooriya et al., "Identification of effective management practices and technologies for lessons learned programs in the construction industry," Journal of Construction Engineering \& Management, vol. 135, no. 6, pp. 531-539, 2015.

[30] T. Kasprowicz, "Quantitative identification of construction risk," Archives of Civil Engineering, vol. 63, no. 1, pp. 63-75, 2017.

[31] T. Zhang, "Application of safety quality hidden danger investigation and management system in subway construction," Value Engineering, vol. 38, no. 20, pp. 57-59, 2019.

[32] Y. Chen, W. Zheng, W. Li, and Y. Huang, "Large group activity security risk assessment and risk early warning based on random forest algorithm," Pattern Recognition Letters, vol. 144, pp. 1-5, 2021.

[33] S. Sultan, "Book review: moving safely: crime and perceived safety in stockholm's subway stations," International Criminal Justice Review, vol. 26, no. 1, pp. 49-50, 2016.

[34] A. Bryson, "Health and safety risks in britain's workplaces: where are they and who controls them?" Industrial Relations Journal, vol. 47, no. 5-6, pp. 547-566, 2016.

[35] Z. Ying, L. Chenshuang, D. Lieyun et al., "Combining association rules mining with complex networks to monitor coupled risks," Reliability Engineering System Safety, vol. 186, pp. 194-208, 2019.

[36] P. Gomba and I. Bradacova, "Critical systems and processes affecting the resilience of subway systems to terrorism risks," Komunikacie, vol. 17, no. 1, pp. 22-27, 2015.

[37] H. S. Lee, H. L. Mun, and S. K. Lee, "Evacuation time at Jongno 3ga subway station considering electric train delays and congestion," Journal of Transportation Security, vol. 11, no. 34, pp. 137-150, 2018.

[38] Y. Lv, X. D. Yan, W. Sun, and Z. Y. Gao, "A risk-based method for planning of bus-subway corridor evacuation under hybrid uncertainties," Reliability Engineering \& System Safety, vol. 139, pp. 188-199, 2015.
[39] J. Peng, J. Quan, and L. Peng, "It application maturity, management institutional capability and process management capability," Journal of Organizational and End User Computing, vol. 31, no. 1, pp. 61-85, 2019. 